\title{
Pahari Distinctiveness without Pahari Language: A Study of Language Attitudes of the Pahari Community
}

\author{
* Dr. Muhammad Gulfraz Abbasi, Associate Professor (Corresponding Author) \\ ** Dr. Zafar Iqbal Khattak, Lecturer \\ *** Dr. Yasir Arafat, Assistant Profess or
}

\begin{abstract}
Pahari language spoken in Murree and its suburbs is in contact with Urdu, the national language of Pakistan. It is also in contact with Punjabi and English. The present study explores the views and attitudes of the Pahari speaking community regarding the Pahari identity and culture vis-à-vis languages like Pahari, Punjabi, Urdu, and English. The study is ethnographic and is based on detailed observation and in-depth interviews of a sample of 91 people belonging to three generations. The study concludes that Pahari speaking community especially the Abbasi tribe, on the whole, claims to protect their culture and identity but gradually each new generation is hesitant in continuing Pahari as the symbol of their identity. As a result, language is, to a great extent, shifting towards Urdu. On a minor level, its shift to English and Punjabi cannot be ignored. The paper also explores certain reasons latent behind this kind of attitude.
\end{abstract}

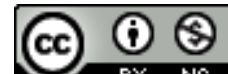

Keywords: Language Attitudes; Pahari Identity; Language Decline; Minority Language

\section{Introduction}

Pakistan is one of the countries of the world where a myriad of languages and dialects across the country are spoken. Almost everyone in this country is bilingual at least, along with a huge number of people who can speak three or more than three languages. According to Ethnologue languages of the world $16^{\text {th }}$ edition (Lewis, 2009), there are 72 indigenous languages besides 5 major languages in Pakistan. These major languages like Urdu and English have gained the reputation of being the languages of power and prestige (Rahman, 2006). With each day, these languages are growing and multiplying. The problem lies with indigenous languages which have hardly any political, economic, or social prestige. In the absence of patronage by the government, the weaker languages lose their vitality and significance in their communities. Pahari spoken in Murree, Gulyat, Circle Bakote, and adjacent areas is also undergoing a process of trial. Pahari is completely banned in educational institutions and most of the families have also adopted Urdu and some English in the ir homes especially when they have to interact with their children. In this way, language transmission is affected.

Pahari language has a rich resource of oral literature, botanical knowledge, and agricultural techniques. Besides, there are songs, proverbs, terse statements of wisdom, etc. But no attempt has so far been made to document and describe this treasure of secret knowledge. But the problem lies in the negative attitude of the people towards this language. This phenomenon can be observed in the case of almost all the weaker languages. In her matched guise test Asif (2005) also drew the same conclusion regarding Siraiki in Pakistan. The participants of the tests showed a negative attitude toward the Siraiki speakers.

\section{Pahari Language and Community Structure}

Pahari is the general name of this language and is used by common people. There are, however, other names of this language such as Dhondi Pahari, or Pahari Pothohari and sometimes, it is referred to as Dhondi Kariali in Pakistan. Dhondi is the name derived from Dhonds whose majority population lives in Murree and adjacent areas in Pakistan. They are also called Abbasis. Therefore, the language is sometimes called Abbasi Pahari. According to Alvi (2006), Dhond Abbasis have their majority in

\footnotetext{
* Department of English, Kohsar University, Murree Email: gulfrazabbasi@gmail.com

** English Language Centre, University of Technology and Applied Sciences Al-Musanna Oman.

Email: aburohaan2004@yahoo.com

*** Faculty of English Studies, NUML Islamabad Email: yasirarafat1980@ gmail.com
} 
Murree, Gulyat, and circle Bakote as compared to other tribes having a limited population. Therefore, in this paper, we will use the name Pahari as it is used by the common population. According to the census conducted in1998, the population of the areas where the Pahari language is spoken is about 176426 persons (Pakistan Bureau of Statistics). The censuses in Pakistan do not usually consider the weaker languages as Romaine (1995:27) believes that the focus of the censuses is basically on the major definitions of languages. Moreover, the Pahari language is not limited to sub-district Murree only; rather its boundaries go beyond the Kashmir border and in Pakistan, it is spoken in some parts of Khyber Pakhtoonkhwa province also. It is declared among the dialects of western Punjabi by Grierson (Grierson, LSI: 1903-1921). Raising objections to the views of Grierson, Karnahi (2007) discussed the unique and distinctive features of the Pahari language along with its culture.

Abbasis, the majority of speakers in these areas, used to live a very secluded life before the creation of Pakistan (Kashmiri, 2006; Abbasi, 1985). They did not accept the occupation of the British in Murree and had several encounters with them leading to hundreds of deaths. As a result, hundreds of people were made captives and sentenced to death. The Gazette of Rawalpindi (Robertson, 1895) mentioned the clash of the occupation forces with the local people. He also mentioned the common feeling of the British that the Abbasis were not reliable people. To keep the difference they lived away from the cities and town centers. After the establishment of Pakistan, they started coming to the cities and started receiving education. Now, with growing interaction with the world and with education, the indigenous population is shifting its loyalties to powerful languages like Urdu and English. Pahari is losing its significance even in the home domain.

\section{Language Identity and Pahari Language}

Speakers holding the uniqueness of a specific community, in reality, engage in positive identity practices, whereas those who go against this employ adverse identity practices to isolate themselves from it (Bucholtz, 1999). Norton (1995) stated that both identity and language are vibrant notions that depend on time and place. However, as far as the Abbasi tribe is concerned, the reality is a bit different. They abandon their indigenous language while keeping their traditions and customs. It is the particular trait of the Abbasi tribe that they are proud of their culture and traditions. They marry within their own families and generally, everything related to their culture is dear to them.

Because of their family pride and superior status (as they define it) they are proud of their distinctive Pahari status. Kashmiri (2006) also talked about their bravery, their culture, traditions, and their family pride. They have strong group ties because of their intermarriages and interrelationships. It is said that strong group ties are important for the vitality of an indigenous language but here the case is different. Their mutual relationships are the same but they are relinquishing their Pahari language and adopting Urdu and other languages of power.

\section{Language Attitudes}

Language attitudes are the feelings and perceptions people hold regarding the language of their community or any other language (Crystal 1992). According to Baker (1992: 11), Attitudes are too opaque to be observed; however, they are a persistent and convenient way of elucidating consistent and reliable patterns in human behavior.

Attitude towards language plays an important role in the preservation or shift of a language. It is a learned behavior that does not transfer from parents to children and hence, can be changed (Baker, 1988). Attitudes are constructed in the subconscious of humans by the political, social, and economic considerations of the society (Ajzen, 1998). Triandis (1971) states that attitudes towards language consist of three things. - affective, cognitive, and conative which in other words mean what a person feels thinks, and finally shows his/her inclination towards an object (cited in Mansoor 1993: 18). Attitudes of the speakers of a community in terms of their language hold primary importance in the maintenance of a language. (Asif, 2005)

Fasold (1984:148) opines that attitudes specific for languages are often the echo of the attitude people hold for the speakers of that particular speech community. The reaction of the people meant for a language variety shows their understanding and attitude for the speakers of that variety of language. Attitude is an important factor in determining the vitality and stability of language. Languages decline or grow according to the attitudes of the speakers towards them. In the case of a favorable attitude, the language continues to hold a tendency of maintenance while the hostile attitude implies deterioration and subsequently loss of language if proper measures are not taken (Gardener, 1985). Attitude toward languages is a very important issue nowadays. It measures the vitality of a 
language by looking at the attitudes of the community members. The languages which have negative attitude by the ir community members are more likely to die and likewise, with each day, indigenous languages are becoming extinct.

\section{Ethnographic Technique}

In this paper, we have adopted the technique of ethnography to observe and record the attitudes of the community members. Ethnography is a technique that helps the researcher to understand the real picture of the community regarding language use and choice of language. Ethnography fundamentally functions as a resource for deciphering the distinctive codes in culture (Ember \& Ember, 2009:1). It is essentially investigative and might require the work of an ethnographer/researcher in the field/community for an extended period (Neyland, 2008). During our fieldwork and interviews, we adopted the role of participant-observers and observed the daily routine of the people. We also observed the use of language by these people in different circumstances. All three generations were observed and we found out what people think regarding the use of Pahari concerning other languages of power and prestige.

During our fieldwork, we also recorded speakers' tendency to use prestigious languages like Punjabi, Urdu, and English and why they did so even though they could speak their own native Pahari language. We could not have been able to study the attitudes of the community members who use more than one language, without resorting to ethnography. Each language has its traits and cultural background and an ethnographic study help in making this cross-cultural study a bit easier (Asif, 2005).

We used participant observation as a technique and interviewed people across the gender, education, income, and age group. We also divided our field into two groups i.e. the rural and the urban. As it is common in Pakistan, the rural area in our study comprises participants having low income and low education rate whereas, in the urban area, people were a bit more educated and had better income resources. It was our observation during fieldwork that the phenomenon of language shift was more frequent in the urban areas. We, therefore, decided to collect data from both rural and urban areas to understand the real situation.

We collected data in the form of diary notes and took down responses of the people to our open-ended questions. We also took notes after observation of the community's use of language.

\section{Research Questions}

Following broad categories of research questions will guide our study:

1. What are the language preferences of the Pahari Community?

2. What is the perception of the character of a Pahari speaker?

3. Can it be introduced in the Schools as a subject? And what could be the response of the people?

4. Is this language endangered? How can it be maintained?

\section{Result and Discussion}

Results of the study are given below:

\section{Language Prefe rence}

As far as the question of preferred language is concerned, forty-seven percent liked Urdu and fiftyone percent liked Pahari in the rural areas. Whereas sixty-seven percent of the total participants chose Urdu, and twenty-two percent opted for Pahari as their favorite language in the urban areas. Around one percent of the rural population voted in favor of Punjabi; however, nobody expressed any liking for English. In the urban area, three percent liked English as a preferred language and one percent liked Punjabi. Hence it appears that the popularity of English and Urdu is increasing at the cost of Pahari. A grandfather of a family pointed out the element of language shame which was restricting people from opting Pahari especially when they had to interact with somebody from an urban area. People bank upon their weak Urdu instead of using Pahari in the urban context. The grandfather further said that women had become more modern as compared to men. Through our participant observation, we also noticed that women paid more importance to Urdu and English. They appeared to be more status-conscious than men.

\section{Things Which Appeal In Pahari and Urdu}

The interviewees had various opinions about the language they prefer to speak. They tended to defend it. A father from the rural area observed, 'Pahari with zabaan ee' (Pahari is a sweet language). We observed many people who claimed that it was a sweet language. They meant to say that Pahari had a 
store of vocabulary to express respect and regards. Another statement is also worth mentioning: Pahari Adab adaab aeli zuban ee (Pahari is a language full of courtesy). However, these ideas are only found in rural areas. However, in the urban areas, people of the grandparent generation showed great respect and a liking for Pahari. They declared it a language of manners. But the parent generation has not shown much enthusiasm for Pahari. One of the female respondents from the urban area saw Pahari as 'a rough or rustic language'. She believed that it was a language of the illiterate and uneducated people of the villages. We also noticed some pejorative remarks and terms for the Pahari-speaking villagers. Kashmiri (2006) observed that Pahari had many heavy and rough words with strong nasal sounds. He gave a list of such words which posed great difficulty in their pronunciation. He is of the view that these words are due to Pahari's Sanskrit origin. These difficult words are the names of places and villages.

A parent belonging to an urban area showed himself to be a deep lover of Pahari. He believed that the Pahari greeting system was matchless: khe hale ya BAL yo khair mair ee'? (how are you, are you alright?'). He also mentioned that this language had many humble. On the other hand, people who acquired Urdu as their first language preferred Urdu to Pahari.

Children living in the urban areas almost had the same sentiments regarding Pahari. The overall atmosphere of the urban area allows Urdu to be spoken and listened to. This atmosphere creates a kind of disgust among the urban children for Pahari. The same is the case with elderly people. They also preferred Urdu as they believed that the future depends on languages of power. They also liked English as it had international importance. We observed that people had a craze for English.

\section{Best Language for Expression}

Fifty-one percent of the rural sample opted for Pahari in response to this question and forty-seven percent voted in favor of Urdu. But from the urban sample around twenty-two percent opted for Pahari for communication purposes while sixty-seven percent favored Urdu and three percent went for English. Though English is one of the most liked languages yet being a foreign language it does not have its grounds. Here Urdu fills the gap and becomes the best language for expression for the people. In the rural areas, Pahari still demonstrates itself as the best language for expression.

In reality, children start learning Urdu and English in schools as they grow up. It is because the medium of instruction is either Urdu or English not only in cities but also in the villages. In this backdrop, even children from rural areas are found to have a deep liking for Urdu and English.

When the children grow up, they start learning Urdu and English in schools. The medium of instruction is strictly Urdu in most of the schools even in the villages. So, some of the children who have learned Pahari as their mother tongue have also said that they can communicate better in Urdu than in any other language even Pahari.

\section{Prefe rence of Language on Radio and TV}

A very few people gave their response to this question. Mostly nobody likes to do anything on TV or Radio. This is all because of shyness especially felt among the rural people. We observed one father who strongly believed that Pahari must be used on TV and radio as it is the only way to make this language popular. This idea is felt by the people that by increasing the prestige of the language on electronic media, Pahari language and culture can be preserved.

One of our female respondents told us that she used to sing Pahari songs at celebrations and weddings. She said that she would make these songs with the help of her friends. She complained that Indian songs had replaced these Pahari indigenous songs. It was her wish that she sang songs on TV and Radio to motivate people to attend to Pahari culture and music.

The data gathered against this question demonstrates that there are people who are desirous to work for the revival of Pahari and that there is a store of cultural things related to Pahari which ne ed to be used and properly stored.

This discussion indirectly shows that a treasure of cultural material is preserved by the old generation. If it is presented on TV or radio or kept in black and white, that precious treasure can be preserved for future generations.

\section{Vie ws about the Character/Personality of Pahari Speaker}

The question was "how do you perceive the character of a person if he is speaking Pahari or Urdu or English? This question was molded in different shapes and often it was asked abruptly to read the mind of the person. 
We received multiple views. Some people refused to give their point of view. It appeared that people liked the personality of those who spoke Urdu or English. The ones who spoke Pahari were not considered much educated or civilized.

In the rural setting, around sixty-six percent of people consider the Pahari speaker as someone having good manners and character. Nineteen percent demonstrate negative feelings. Whereas in the urban areas, thirty-two percent take it as positive while ten percent consider it in a negative sense. The remaining fifty-seven percent hesitated in giving their views. Pahari has become a symbol of ignorance backwardness, weakness, and ignorance for their speakers. Many native speakers of Pahari started speaking Urdu when we talked to them in Pahari. In this way, many people try to hide their efficiency of Pahari.

\section{Vie ws about Pahari Accented Urdu or English}

We observed that people do not like someone who speaks Urdu with a Pahari accent. It is a matter of shame for all of them. Twenty-one percent from the rural side consider it normal while the rest consider it very bad. From the urban sample, only one person out of forty says that it is good and normal while all others show their disgust about it. People often believe that Pahari being a nasalized language disturbs the purity of English and Urdu. We also happen to observe a school teacher who criticizes the speakers of Urdu after a speech competition. According to her the Urdu of the villagers with the wrong pronunciation of words like'paharu $\sim$ ', ma idanu $\sim$, deryau $\sim$ (mountains, plains, rivers) is not right.

\section{About Usage of Pahari in Domains Other than Home}

This question was particularly elicited from the grandparent's and parents' generation and results demonstrate that around seventy-seven percent are in favor of Pahari usage other than home domain. Twenty-two percent of people of the sample say that it should not be used other than home. The study from the urban areas demonstrates that thirty percent of the people believe that it should be used outside the home while sixty-nine percent say that it should not be used other than the home domain. Fifty percent of the grandparents belonging to urban areas also believe that no compulsion should be imposed on children to speak Pahari outside the home domain. It is also very interesting that thirty-six percent of the people (parent generation) from the rural side also of the view that Pahari may not be imposed to be used other than home.

This analysis shows how people like this Pahari to be restricted to their homes. This is happening as language is not being given its due status in society which ultimately demotivates the masses. This does not mean that language is preserved in the home rather it is a clear indication that it will soon be dismissed in the homes as well.

We found womenfolk to be more conscious of the dangerous effects (as they say) it might cast on the personalities of their children. Sometimes it seems that if their children speak Pahari outside their homes, is like having ill manners. So women mostly discourage their kids from speaking Pahari with their guests

During our observation, we noticed that women asked their children to use Urdu with us. In one case a mother introduced her small daughter to us and informed us in Urdu:

(She knows how to speak Urdu but she is shy)

So Pahari language is being controlled and restricted by its native speakers and there is no encouragement by the parents on the whole.

\section{Views about Teaching Pahari in Schools as a Subject}

Pahari is not taught as a subject in schools. Responses to our interview question whether we should have it as a subject or not in schools, majority of the people said that it should not be included as a subject in schools.

One mother opined in connection with this question:

'Kids are already burdened with subjects like English, Urdu, and Arabic, what is the use of

Pahari'

There were a few people who wished to hear that Pahari should be brought in as a subject. One father said that it was a very good proposal and that children must have an idea about their culture and language. Therefore, he said that Pahari must be taught as a subject.

\section{About Studying Pahari Subject in Schools}

People, by and large, do not want Pahari to be taught as a subject in schools. Ironically, some people seemed to be in favor of Pahari but refused to accept it as a subject in schools. When asked they 
described the economic reason. Pahari did not have a good future for their coming generations. It did not guarantee any success largely because Pahari was the official language or national language. Counting these weaknesses, the participants mostly did not vote for Pahari considering it an extra burden on the students. As far as Pahari as a subject is concerned, most of the people had negative attitudes toward this language. Eighty-two percent of people said that they would not persuade their kids to go for the Pahari subject if they were to study it. Some participants took it an opportunity to say that many important science subjects could be introduced rather than bringing Pahari into this fold.

\section{About Pahari Programs on Electronic Media}

The participants were asked to give their views regarding Pahari programs on TV. Eighty-seven percent of them said that there should be programs on TV. Thirty percent of the urban sample said that there was no need for this. It is interesting to note that the participants who showed their interest in Pahari programs indicated funny Pahari programs. For them, the use of Pahari on TV or Radio platform is also a funny thing in itself.

\section{Fe elings about childre n's incompetence in Pahari}

Around a hundred percent of the participants said that it was not at all appreciable if the ir children did not speak Pahari. People considered it a bad thing. A very few people declared the inability to speak Pahari as not bad. We also noticed that some families both from urban and rural sides were very conscious about Urdu usage. If at all their children turn to Pahari by mistake, they would snub them for this delinquent behavior. People are sometimes confused regarding Pahari. It looks that people, by and large, are not against the use of Pahari, but at the same time, they wanted themselves to be recognized as educated and well-behaved and that is only possible if they are Urdu speakers (as it appears).

\section{About fe elings over the extinction of Pahari}

In response to this question, eighty-eight percent of respondents from the rural area understand this thing as a bad omen. From the urban sample, seventy-five percent consider the death of Pahari as a bad sign. They can hardly believe that their language could die away. This feeling was observed in the rural areas with more strength than the urban areas. The reason behind this is that Pahari is spoken mainly in the rural areas and these people are more concerned about it while on the urban side, people have other things attached with language. So for them, the language with power, economy, and prestige matters more than merely a language.

\section{Vie ws about the maintenance of Culture and Language if language died}

Responding to this question, ninety percent of people confessed that they did not do anything to maintain the identity and culture of their community if they ever lost their mother tongue. The respondents seemed to have deep feelings for the ir language. However, practically, they were leaving their language to earn a better future for their children. Moreover, it is transpired during our interviews that the public did not understand the real function of a mother tongue. They did not know how many things we're attached to a language such as culture and identity.

\section{About the importance of mainte nance of Pahari}

In reply to the above question, seventy-eight percent of the sample from the rural area and forty-seven percent from the urban area showed their belief that maintenance of Pahari was very important for them. Collectively, sixty-five percent of the total sample, both from the rural and urban areas, favored the maintenance of Pahari in its original shape. The negative remarks were recorded from the children's generation. A very few children wanted Pahari to be maintained. People were found to have support for Pahari and they knew that it bore their culture and identity, but practically most of them did not take any responsibility to maintain it. So it shows that for them practically, the death of Pahari will not affect them a lot.

\section{About maintenance of Pahari as a difficult task or otherwise}

According to the respondents, it is very hard to maintain Pahari. Some of them gave examples of the use of Pahari in the recent past and then its use in the present. So the gap is increasing day by day as they believed. Several participants did realize that Pahari was losing its grip with every single day. The urban people showed their satisfaction that no one could stop Urdu as it is the national language and a language of prestige. Grandparents' generation complained that it was all due to the media which had introduced many new languages and thus the local culture and languages were dying. 


\section{Vie ws about the people who frequently s peak Urdu}

When it was checked whether people like those who spoke Urdu, it transpired that people had a good opinion about those who frequently spoke Urdu. Sixty-one percent of the people said that they favored those who mostly spoke Urdu. Thirty-eight percent of the people had a negative attitude towards those people. Children's generation, however, favored Urdu speakers. Urdu, for most of them, was a language of respect and dignity. Hence their views about the speakers of Urdu were that they were intelligent and well-mannered.

\section{Attitude towards Speakers who tend to mix other languages in Pahari}

Ninety percent of the people from cities, during our interviews and participant observation, approved mixing of other languages in Pahari. On the other hand, forty-one percent of the sample approved the mixture of other languages in Pahari. This question helped in understanding the difference of opinion between the urban and rural people. Rural people want Pahari in its original shape as they are close to their language whereas, urban people do not. So, whether it is mixed with other languages or not, they do not have any problem with it. Those who favored code-mixing in Pahari believed that mixing of other languages is good as it provides an opportunity to the Pahari language to make itself more worthwhile for communication. Those against it, say that it is just a mock show through which some people try to show themselves very educated. For them, it is no more than just snobbery.

\section{Pahari is the foreign accent}

It was observed during fieldwork that the people, who used Pahari with an Urdu accent, were considered fine because it refers to the education of that group of people. Most of the Pahari people do not have any other accent other than that of Pahari. The fact is that people have unconsciously or even consciously great respect and regard for Urdu and English. However, they were not much in favor of bringing words from other languages.

\section{Conclusion}

The study concludes that the Pahari community has a negative attitude towards its own Pahari language. There are many reasons for this negative attitude. They find no way to progress with the Pahari language. Although, grandparents and parent generations have preserved Pahari to a great extent, yet they do not, unconsciously, want it to be preserved by their children. In other words, the transmission of Pahari has been much reduced in the home domain. It is generally said that the home domain is the last powerful resort of a language. If the language survives in the home domain, the language cannot die at all. But in the case of the Pahari language, people have generally started using Urdu and English with their children because of prestige, economic value, and marketability. So the Pahari language speaker is downgraded as less intelligent, having less income, and being less civilized. It is the need of the hour to work for the revitalization of the Pahari language. If the attitudes towards this language remain the same in the future, the language may not survive after two generations. The people may be made aware of the fact that their mother tongue/native language is a precious asset and the community should never lose this asset.

\section{References}

Abbasi, N.E. (1985). Tareekh-e-Murree [The History of Murree]. Lahore: Abbasi Publishers.

Ajzen, I. (1998). Models of Human Social Behaviour \& their application to health psychology, psychology, \& health, 13, 735-739.

Alvi, U. (2006). Muqaddama: Assan nay Nabi Pak Ore. [Preface to Our Dear Holy Prophet PBUH] Karachi: Idara Tehqeeq-ul-Awan Pakistan.

Asif, S. I. (2005a) Siraiki: A sociolinguistic study of language desertion. Unpublished Ph.D. thesis, Lancaster University, UK.

Baker, C. (1988). Key issues in Bilingualism \& Bilingual Education. Clevedon: Multilingual Matters.

Baker, C. (1992). Attitudes \& Language Avon: Clevedon. Reyhner, John (ed.) (1997)

Bucholtz, Mary. 1999. "You da man: Narrating the Racial Other in the Production of White Masculinity." Journal of Sociolinguistics 3(4): 443-460

Crystal, D. (1992). An encyclopedic dictionary of language \& languages. Cambridge, MA: Blackwell.

Ember, C. R. \& Ember, M. (2009). Cross-cultural research methods. Lanham: Altamira Press.

Fasold, R. (1984). The sociolinguistics of society. Oxford: Basil Blackwell.

Gardner, R.C. (1985). Social psychology \& second language learning: The role of attitudes \& motivation. London: Edward Arnold Publishers. 
Grierson, G. (1903-1921). Linguistic Survey of India. Reprinted as Linguistic Survey of Pakistan, vol IV, Lahore: Sang-e-Meel (n.d.).

Karnahi, M. K. Q. (2007). Pahari aur Urdu: Aik Taqabli Jaiza [Pahari \& Urdu: A Comparative Study]. Pakistan: National Language Authority.

Kashmiri, L. (2006) Khayaban-e-Murree. Rawalpindi: Babar Booksellers.

Lewis, M. Paul (ed.), (2009). Ethnologue: Languages of the World, Sixteenth edition. Dallas, Tex.: SIL International. Online version: http//www.ethnologue.com/.

Mansoor, S. (1993). Punjabi, Urdu, English in Pakistan: A Sociolinguistic Study. Lahore: Vanguard.

Neyland, D. (2008). Organizational Ethnography. Los Angeles [u.a.]: Sage. Pakistan Bureau of Statistics. https://www.pbs.gov.pkunits 10-05-2021/content/area-population-administrative-

Rahman, T. (2006a). Language \& Polities in Pakistan. Karachi: Oxford University Press

Robertson, F. (1895) ed. Reprint (1990). Gazetter of the Rawalpindi District 1893-94. Lahore: Sange-MeelPublications.

Romaine, S. (1995). Bilingualism. Blackwell Publishers: UK. 